\title{
Effect of Ionic Liquid Structure on the Oxygen Reduction Reaction under Humidified Conditions
}

Simon Doblinger ${ }^{A}$, Junqiao Lee ${ }^{A}$, Debbie S. Silvester ${ }^{A, B}$

${ }^{A}$ Curtin Institute for Functional Molecules and Interfaces, and School of Molecular and Life Sciences, Curtin University, GPO Box U1987, Perth, WA 6845, Australia

BCorresponding author. Email: d.silvester-dean@curtin.edu.au

\begin{abstract}
The oxygen reduction reaction (ORR) is widely studied in room temperature ionic liquids (RTILs), but typically in dry environments. Since water is known to affect diffusion coefficients and reaction outcomes, the influence of water on the ORR is expected to be significant. We have therefore studied the effect of RTIL structure on the ORR at different relative humidity $(\mathrm{RH})$ levels using cyclic voltammetry. A broad range of cations including imidazolium-, ammonium-, pyrrolidinium-, pyridinium, sulfonium- and phosphonium-, and anions such as $\left.\left[\mathrm{BF}_{4}\right]^{-},\left[\mathrm{PF}_{6}\right]^{-}, \mathrm{NTF}_{2}\right]^{-}$and $[\mathrm{FAP}]^{-}$were employed. The cation was found to have a large effect on the reduction current of oxygen even at low humidity levels ( $<40 \mathrm{RH} \%$ ), whereas the anion mainly influenced the current at higher humidity levels ( $>65 \mathrm{RH} \%$ ). Consequently, the choice of cation needs to be carefully considered when selecting a suitable RTIL solvent for oxygen reduction in humidified environments. The size, structure and hydrophobicity of the ions was found to dictate the degree at which the RTIL is susceptible to changes in humidity. The physical characteristics of the RTIL electric double layer on platinum electrode surfaces were further investigated by atomic force microscopy force-curve studies in three selected RTILs. The results suggest that there is a significant amount of water incorporated the electrode-RTIL interface in $\left[\mathrm{C}_{2}\right.$ mim $]\left[N T f_{2}\right]$ and $\left[\mathrm{N}_{4,1,1,1}\right]\left[\mathrm{NTf}_{2}\right]$, but not in the more hydrophobic $\left[\mathrm{P}_{14,6,6,6}\right]\left[\mathrm{NTf}_{2}\right]$. The presence of moisture has a significant impact on ORR currents in $\left[\mathrm{C}_{2} \mathrm{mim}\right]\left[\mathrm{NTf}_{2}\right]$ even at extremely low humidity levels, which was verified by the higher level of water incorporation in $\left[\mathrm{C}_{2} \mathrm{mim}\right]\left[\mathrm{NTf} f_{2}\right]$ compared to $\left[\mathrm{N}_{4,1,1,1}\right]\left[\mathrm{NTf} f_{2}\right]$ and $\left[\mathrm{P}_{14,6,6,6}\right]\left[\mathrm{NTf}_{2}\right]$. Hydrophobic and large RTIL cations and anions (e.g. $\left[\mathrm{P}_{14,6,6,6}\right]^{+}$and $\left[\mathrm{FAP}^{-}\right)$are recommended for applications where a stable ORR current response is required under humidified conditions.
\end{abstract}

\section{Keywords}

Oxygen reduction reaction; humidity; room temperature ionic liquids; cyclic voltammetry; atomic force microscopy; electrical double layer; oxygen sensing. 


\section{Introduction}

The reliable monitoring of gases under extreme conditions is an important criteria for sensors in industry, and is especially important for health and safety requirements. ${ }^{1}$ Commercially available sensors usually consist of a threeelectrode setup, with an aqueous based electrolyte (usually water $/ \mathrm{H}_{2} \mathrm{SO}_{4}$ ), and a gas permeable membrane that prevents solvent evaporation at high temperatures. ${ }^{2}$ However, this membrane also reduces the diffusion rate of gases towards the electrode. ${ }^{3}$ An alternative, proposed by Buzzeo et al., is the use of room-temperature ionic liquids (RTILs) as a non-volatile electrolyte, which removes the need for a membrane layer. ${ }^{4}$

RTILs are composed of cations and anions that are liquid at room temperature due to asymmetry in at least one of the ions ${ }^{5}$ and weaker ion-ion interaction forces. ${ }^{6}$ RTILs are increasingly used in synthesis, ${ }^{7}$ as well as in electrochemistry applications, ${ }^{8-11}$ due to their promising characteristics, such as negligible volatility, high stability up to certain temperatures without decomposition, and high conductivity. ${ }^{12}$ Due to their intrinsic conductivity, they have been extensively explored as alternative electrolyte materials. ${ }^{13}$ The wide electrochemical windows (ca. 4-6 V) ${ }^{14}$ of these solvents make them suitable candidates for electrochemical sensing applications; with the detection of gaseous analytes like hydrogen, oxygen or ammonia already reported in the literature. ${ }^{15}$ However, the hygroscopic nature of RTILs is an issue for their use in practical environments that currently hinders their implementation in commercial membrane-free sensors. The tendency for RTILs to absorb moisture can lead to instability and unreliability in the measurements when the gas-sensor is subjected to real-atmospheres with changing humidity levels. ${ }^{16-18}$ It is hence clear that water is a significant impurity in RTIL-based gas-sensors that need to be investigated; this can be indirectly monitored by studying the oxygen reduction reaction (ORR).

The ORR has been widely reported in aprotic RTILs for the purposes of oxygen gas detection. ${ }^{4,8,19-20}$ Katayama et al. published an almost reversible redox couple in ammonium-based ionic liquids with a current density ratio of $0.97 .^{21}$ It has also been shown that the reduction of oxygen can undergo different mechanistic pathways, depending on the presence and concentration of protic species such as water, which could cause a shift from a $1 \mathrm{e}^{-}$(equation 1 ) to a $2 \mathrm{e}^{-}$ (equation 2 ) or even a $4 \mathrm{e}^{-}$(equation 3 ) reduction reaction. ${ }^{22-24}$ This significantly complicates the reliable calibration of a sensor when exposed to different humidity levels, since water can act as an effective proton source, ${ }^{25}$ opening up electrochemical reaction pathways that are dependent upon the concentration of water.

$$
\begin{aligned}
& \mathrm{O}_{2}+e^{-} \rightarrow \mathrm{O}_{2}^{-\bullet} \\
& \mathrm{O}_{2}+2 \mathrm{H}^{+}+2 e^{-} \rightarrow \mathrm{H}_{2} \mathrm{O}_{2} \\
& \mathrm{O}_{2}+4 \mathrm{H}^{+}+4 e^{-} \rightarrow 2 \mathrm{H}_{2} \mathrm{O}
\end{aligned}
$$

Therefore, several groups (including ours), have used hydrophobic RTILs, ${ }^{26-28}$ or mixed the electrolyte with a hydrophobic polymer to reduce the water uptake. ${ }^{29-30}$ However, this did not eliminate the water absorption problem entirely.

When examining the impact of absorbed moisture on the electrochemical processes at the electrode-RTIL interface, the structure of the RTIL at the interface must be taken into account. ${ }^{17}$ Research performed by other groups has shown 
that as with conventional solvents, ionic liquids form electrical double layers (EDLs) at the electrode/solution interface. ${ }^{31-32}$ The EDL structure at the electrode interface could have a severe impact on the transport of analytes such as gases or moisture towards the surface, which is required to induce an electrochemical reaction. Several methods including atomic force microscopy (AFM), ${ }^{33-34}$ surface force apparatus (SFA), ${ }^{35}$ neutron reflectometry, ${ }^{36}$ sum frequency generation vibrational spectroscopy (SFG-VS) ${ }^{37}$ and surface-enhanced infrared absorption spectroscopy (SEIRAS) ${ }^{38}$ have been used to try to elucidate this behaviour. For RTILs, the thickness and number of layers at the electrode is strongly dependent on the charge density at the surface and the nature of the cation and anion. Depending on the cation and anion structure, the EDL that is formed when a potential is applied can be either more or less pronounced. ${ }^{34,39-41}$ Single as well as ion-pair layers have been detected at the interface using AFM. ${ }^{33,42}$ With regards to layer thickness, theoretical simulations of these EDL structures are in good accordance with experimental data. ${ }^{43} \mathrm{It}$ is already well known that when the electrode is highly charged, more than one cation or anion layer can be formed near the electrode ${ }^{44}$ which means that either the cation-analyte or anion-analyte interactions may influence the concentration profile of various dissolved species. Hence, knowledge of the EDL structure is crucial to explain changes in the response in electrochemical experiments. However, the structuring of RTILs on surfaces in the presence of other species (e.g. oxygen or water) is not very well understood.

Computational studies have been carried out to investigate the influence of adsorption of water ${ }^{45}$ or ferrocene ${ }^{46}$ in RTILs. However, despite the extensive literature published on the structure of the EDL of RTILs, experimental studies on the influence of species, such as absorbed gases or water, are still lacking. ${ }^{23}$ Characteristics of the RTIL, such as the charge carrying atom, as well as the alkyl chain length, number, and position(s) on both the cation and the anion, appear to be key determining factors of water sorption properties of RTILs. COSMO-RS predictions have shown that there is a strong interaction between water and ionic liquid anion in the bulk phase. ${ }^{47}$ This means that for different RTILs that have the same anion, the mutual solubility of water only varies slightly, while for RTILs with same cation and different anions, the effect is more pronounced. ${ }^{47}$ It should also be noted that the bulk-phase behaviour of water in RTILs can be very different to the behaviour near a charged electrode surface. For example, Bi et al. ${ }^{48}$ showed that the electrosorption of water on electrodes in humid, hydrophobic ILs was higher than in hydrophilic RTILs even though the bulk phase solubility of water showed the opposite trend. Therefore, the effect of water on electrode processes may be different to the trends expected based on the hydrophobicity/hydrophilicity of the RTILs.

In this work, we demonstrate the influence of the RTIL structure at the EDL - varying both the cation and the anion - and show its effect on the ORR in humidified environments using cyclic voltammetry (CV). Six different cation types (imidazolium-, pyrrolidinium-, pyridinium-, ammonium-, sulfonium- and phosphonium-) with different alkyl chain lengths and several different anions are analysed. Atomic force microscopy (AFM) is then performed under unbiased and biased conditions to provide insights into the impact of water on the EDL structure of RTILs on a charged surface, and to give an explanation for the electrochemistry results. 


\section{Experimental}

\subsection{Chemical reagents}

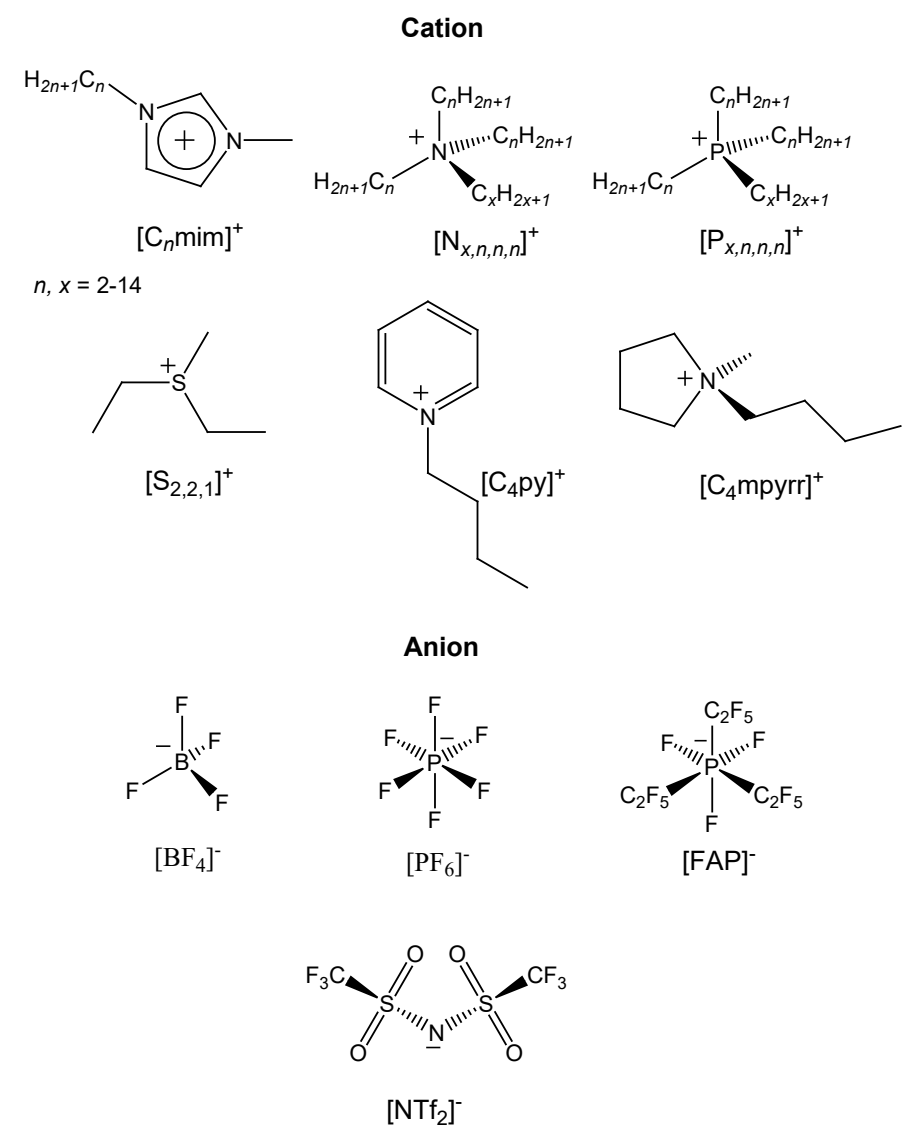

Figure 1. Chemical structures and abbreviations of the room temperature ionic liquid cations and anions used in this study.

All RTILs were obtained at the highest purities possible. Diethylmethylsulfonium bis(trifluoromethylsulfonyl)imide ([ $\left[S_{2,2,1}\right]\left[\mathrm{NTf}_{2}\right], 99 \%$, loLiTec-Ionic Liquids Technologies $\mathrm{GmbH}$, Heilbronn, Germany), butyltrimethylammonium bis(trifluoromethylsulfonyl)imide ([ $\left.\mathrm{N}_{4,1,1,1}\right]\left[\mathrm{NTf}_{2}\right], 99,5 \%$, loLiTec), butylpyridinium bis(trifluoromethylsulfonyl)imide ([ $\mathrm{C}_{4}$ Py][NTf $\left.f_{2}\right], 99 \%$, loLiTec), trihexyltetradecylphosphonium tris(pentafluoroethyl)trifluorophosphate $\left(\left[\mathrm{P}_{14,6,6,6}\right][[\mathrm{FAP}]\right.$, $>98 \%$, Merck Pty. Ltd. Kilsyth, Victoria, Australia), butylmethylpyrrolidinium bis(trifluoromethylsulfonium)imide ([ $\left.\mathrm{C}_{4} \mathrm{mpyrr}\right]\left[\mathrm{NTf}_{2}\right], 99.5 \%$, loLiTec), 1-ethyl-3-methylimidazolium bis(trifluoromethylsulfonyl)imide ([ $\left.\mathrm{C}_{2} \mathrm{mim}\right]\left[\mathrm{NTf}_{2}\right]$, 99.5 \%, loLiTec), 1-ethyl-3-methylimidazolium tris(pentafluoroethyl)trifluorophosphate ([C ${ }_{2}$ mim][FAP], for synthesis $>98 \%$, Merck), 1-butyl-methylimidazolium bis(trifluoromethylsulfonyl)imide ([C ${ }_{4}$ mim] $\left[\mathrm{NTf}_{2}\right], 99.5 \%$, loLiTec), 1-butyl3-methylimidazolium tris(pentafluoroethyl)trifluorophosphate ([ $\left.\mathrm{C}_{4} \mathrm{mim}\right][\mathrm{FAP}]$, high purity $>99 \%$, Merck), 1-butyl-3methylimidazolium tetrafluoroborate $\quad\left(\left[\mathrm{C}_{4} \mathrm{mim}\right]\left[\mathrm{BF}_{4}\right], \quad 99 \%, \quad\right.$ loLiTec), 1-butyl-3-methylimidazolium hexafluorophosphate $\left(\left[\mathrm{C}_{4} \mathrm{mim}\right]\left[\mathrm{PF}_{6}\right]\right.$, high purity $>99 \%$, Merck), 1-hexyl-3-methylimidazolium tris(pentafluoroethyl)trifluorophosphate ([C 6 mim][FAP], high purity, Merck) were used as received. Trihexyltetradecylphosphonium bis(trifluoromethylsulfonyl)imide $\left(\left[\mathrm{P}_{14,6,6,6}\right]\left[\left[\mathrm{NTf}_{2}\right]\right)\right.$ was kindly donated by the group of Professor Chris Hardacre (now at the University of Manchester, UK) when he was located at Queens University Belfast, UK. 1-hexyl-3-methylimidazolium bis(trifluoromethylsulfonyl)imide ([ $\left.\mathrm{C}_{6} \mathrm{mim}\right][\mathrm{NTf} 2], 99 \%$, loLiTec) was kindly donated by Professor Rob Atkin (University of Western Australia). The RTIL heptyltriethylammonium 
bis(trifluoromethylsulfonyl)imide $\left(\left[\mathrm{N}_{2,2,2,7}\right]\left[\mathrm{NTf}_{2}\right]\right)$ was synthesized according to standard literature procedures ${ }^{49}$ (see electronic supplementary information (ESI) Figure S1 for the NMR data). The chemical structures of the ionic liquid cations and anions used in this study are summarized in Figure 1. Ultrapure water with a resistivity of $18.2 \mathrm{M} \Omega \mathrm{cm}$ prepared by a Milli-Q laboratory water purification system (Millipore Pty Ltd., North Ryde, NSW, Australia) was used for humidifying the oxygen gas stream. Acetone (CHROMASOLV ${ }^{\circledR}$, for HPLC, $\geq 99.0 \%$, Sigma-Aldrich) and ferrocene (98\%, Sigma-Aldrich) were used as received. A $1 \mathrm{M}$ stock solution of $\mathrm{H}_{2} \mathrm{SO}_{4(\mathrm{aq})}$ (prepared with ultrapure water from a 95-98 wt\% $\mathrm{H}_{2} \mathrm{SO}_{4}$ solution, Ajax Finechem, WA, Australia) was used for the activation of the thin-film electrodes. High purity oxygen gas (>99.5\%) and high purity nitrogen gas (99.99\%) cylinders were purchased from BOC Gases (Welshpool, WA, Australia).

\subsection{Electrochemical experiments}

CV measurements were performed with a PGSTAT101 Autolab potentiostat (Metrohm Autolab, Gladesville, NSW, Australia) interfaced to a computer with NOVA 1.11 software. The electrochemical cell was housed in an aluminium Faraday cage to reduce electromagnetic interferences. The working electrode (WE), counter electrode (CE) and reference electrode (RE) of the thin-film electrodes (TFEs) (ED-SE1 Pt, MicruX Technologies, Oviedo, Spain) are composed of platinum $(\mathrm{Pt}$ ) deposited on a Pyrex substrate, with a WE diameter of $1 \mathrm{~mm}$. Wires were soldered onto the connecting pads of the chip. The WE was electrochemically activated prior to each experiment by CV cycling (> 300 times) at $1 \mathrm{Vs}^{-1}$ in nitrogen purged $1 \mathrm{M} \mathrm{H}_{2} \mathrm{SO}_{4(\mathrm{aq})}$ between -0.75 and $+0.7 \mathrm{~V}$. The activated chips were then rinsed twice with ultrapure water and acetone before drying under a nitrogen stream. To account for the unstable Pt quasiRE on the TFE, modification of the RE with lithium iron phosphate (LFP) (previously developed by our group ${ }^{50}$ ) was attempted. However, the interaction of superoxide with the LFP material led to a change in ORR peak shape and current over consecutive scans, making measurements unreliable. Therefore, to investigate the influence of humidity on CV peak potentials for selected RTILs, ferrocene was added in-situ, and potentials were shifted such that the midpoint of the ferrocene/ferrocenium $\left(\mathrm{Fc} / \mathrm{Fc}^{+}\right)$redox couple was at $0 \mathrm{~V}$.

Seven $\mu \mathrm{L}$ of the ionic liquid was drop-cast to cover all three electrodes on the TFE and purged for at least $45 \mathrm{~min}$ in a high purity nitrogen stream at a flow rate of $500 \mathrm{~mL} \mathrm{~min}^{-1}$ to remove dissolved gases and impurities such as oxygen and carbon dioxide. The relatively high volume of electrolyte on the small chip (compared to our previous experiments) ensures that the electrogenerated products from each scan can be effectively diluted, so that their accumulation is negligible. For all oxygen measurements, the integrated CE and WE were used. After purging the electrolyte with nitrogen gas for at least $45 \mathrm{~min}$, oxygen was introduced into one arm of a modified glass T-cell. ${ }^{51}$ The oxygen line was additionally connected to a humidity generator (Owlstone Humidity Generator OHG-4, Owlstone, Cambridge, UK) that separates the gas flow into 'dry' and 'wet' streams by bubbling the gas through a container of $400 \mathrm{~mL}$ of ultrapure water at a flow rate of $500 \mathrm{~mL} \mathrm{~min}{ }^{-1}$. Adjusting the dry to wet flow ratio results in different humidity levels and the measured dew point $\left(T_{\mathrm{d}}\right)$ was converted to obtain the relative humidity percentage $(\mathrm{RH} \%)$, using equation $(4)^{52}$ :

$$
R H \%=100 \% * 10^{m\left(\frac{T_{d}}{T_{d}+T_{n}}-\frac{T_{a m b}}{T_{a m b}+T_{n}}\right)}
$$


with the constants $m=7.59$ and $T_{n}=240.73{ }^{\circ} \mathrm{C}$, the ambient temperature $T_{\text {amb }}$ and the dew point $T_{\mathrm{d}}$ in ${ }^{\circ} \mathrm{C}$ (Humidity Conversion Formulas, Vaisala)..$^{53}$ The dew point was measured at a location close to the electrochemical cell to ensure that the actual humidity introduced into the T-cell is not affected by condensation or adsorption along the tubing (see Figure 2).

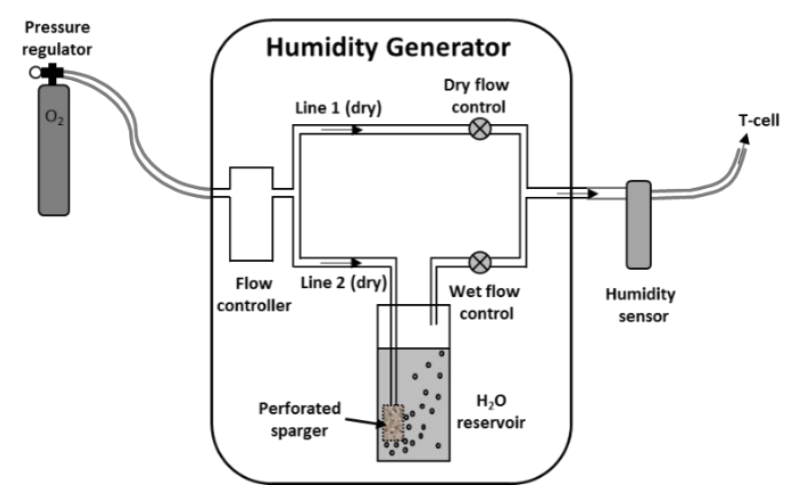

Figure 2. Schematic of the gas humidifying system used for voltammetric measurements on thin-film electrodes (TFEs).

Since the humidity generator is not able to detect humidity levels lower than $1 \mathrm{RH} \%$, measurements were conducted at a starting humidity level of $\sim 1 \mathrm{RH} \%$. It is also known in the literature that even with prolonged vacuum purging, a significant amount of water is retained (in the $\sim 10-100$ ppm range) ${ }^{54}$ in the RTIL. An equilibration time of 45 min was employed before performing CV scans at each humidity level to ensure that the gas was fully saturated, particularly into the most viscous ionic liquid. Repeated $\mathrm{CV}$ scans for $\mathrm{O}_{2}$ reduction were carried out under constant humidity conditions to identify the duration for a stable peak current to be achieved (see Figures S3-S6 in the supporting information). 45 mins was found to be more than sufficient for equilibrium to be attained across all RTILs and humidities. Hence, before the commencement of experiments, the RTILs were also first purged under $\mathrm{N}_{2}$ gas for more than 45 mins. It is noted that water uptake times of up to 180 min were observed for RTILs at different humidity environments, ${ }^{55}$ but that study employed a larger volume of ionic liquid and used a static set-up, in contrast to the large surface-to-volume (seven microliter RTIL droplet spread out over a thin-film electrode) and the constant flow system used in our experiments.

All experiments were carried out at least in triplicate and all data points were used to establish the trendline that was fitted by a logistic regression analysis. In order to remove the contributions caused by different solubilities and diffusion coefficients in the RTILs, the currents were normalised, where the measured currents at different humidities were divided by those measured at $1 \mathrm{RH} \%$.

\subsection{AFM measurements}

Atomic force microscopy (AFM) experiments were carried out with a Bruker Dimension Icon interfaced to a computer with NanoScope 9.4 software in contact mode using activated Pt TFEs. Force curves were collected continuously with a scan rate of $0.16 \mathrm{~Hz}$ while the ramp size was between 100 and $160 \mathrm{~nm}$. A silicone barrier (Selleys Silicone Sealant, Padstow, NSW, Australia) was constructed around the electrode cell to confine the ionic liquid during 
the AFM measurements. All experiments were performed with a silicon nitride AFM tip (SNL-10, spring constant $0.35 \mathrm{Nm}^{-1}$ ). The tips were carefully cleaned in sulfuric acid (1 M) for $60 \mathrm{~s}$, washed with ultrapure water and acetone, and finally dried under a nitrogen stream. Measurements were conducted on an uncharged and a negatively charged electrode surface under mildly humidified conditions (ca. $40 \mathrm{RH} \%$ ). When the electrode was negatively polarised, rapid formation and growth of $\mathrm{H}_{2}$ bubbles were observed at <-1 $\mathrm{V}$ in $\left[\mathrm{C}_{2} \mathrm{mim}\right]\left[\mathrm{NTf}_{2}\right]$ (see ESI for a detailed discussion). Hence, a less negative biasing potential of $-0.8 \mathrm{~V}$ was chosen for the studies.

\subsection{Computational estimation of ion dimensions and water-affinity}

The structure of several RTIL cations and the $\left[\mathrm{NTf}_{2}\right]^{-}$anion was computationally optimised (Spartan '14, Wavefunction, Inc., California, USA) with a semi-empirical approach, using the parameterized model number 3 (PM3) method for single isolated ions in vacuum. For the cations with significant degree of freedom (e.g. $\left[\mathrm{N}_{4,1,1,1}\right]^{+}$and $\left.\left[\mathrm{P}_{14,6,6,6}\right]^{+}\right)$the alkyl chains were pre-oriented before the structures were minimised. The dimensions were estimated from the optimised structures based on their expected orientations. Re-positioning of the RTIL side-chains, due to interactions with the electrode surface (unbiased/negatively-biased), and neighbouring species (e.g. cation, anion, water) can affect the layer thickness created by the cations/anions. It is noted that the computationally obtained values are simply to aid with the analysis of AFM force-curve measurements; a more thorough computational investigation of layer thicknesses is beyond the scope of this work. The value estimated for $\left[\mathrm{C}_{2} \mathrm{mim}\right]^{+}$agrees well with literature. ${ }^{56}$

The computationally estimated orthogonal dimensions, corresponding space-filling (CPK) volumes for each of the ions and the water molecule, as well as their solvation energies (SEs) are summarised in Table S1. The CPK volumes follow the trend:

$$
\begin{gathered}
{\left[\mathrm{P}_{14,6,6,6}\right]^{+}>>>\left[\mathrm{N}_{7,2,2,2}\right]^{+}>[\mathrm{FAP}]^{-}>\left[\mathrm{C}_{6} \mathrm{mim}^{+}>\left[\mathrm{C}_{4} \mathrm{mpyrr}\right]^{+}>\left[\mathrm{C}_{4} \mathrm{mim}\right]^{+} \approx\left[\mathrm{C}_{4} \mathrm{py}\right]^{+}>\left[\mathrm{NTf}_{2}\right]^{-} \approx\left[\mathrm{N}_{4,1,1,1}\right]^{+}>\left[\mathrm{C}_{2} \mathrm{mim}^{+} \approx\left[\mathrm{S}_{2,2,1}\right]^{+}>>[\mathrm{PF}]^{-}>\right.\right.} \\
{\left[\mathrm{BF}_{4}\right]^{-}>\mathrm{H}_{2} \mathrm{O}}
\end{gathered}
$$

The PM3 calculated SEs of selected single isolated RTIL molecules are also listed in Table S1 to provide the local affinity of each ion towards surrounding water molecules; the greater the SE value, the more hydrophobic the molecule is likely to be. It is noted that these values are relevant on the inter-molecular scale but may not apply for the bulk RTIL as they do not account for RTIL-RTIL and bulk interactions, and hence may not coincide with bulk properties of hygroscopicity and hydrophobicity. The SEs (listed in Table S1) follow the trend:

$$
\begin{aligned}
& {\left[\mathrm{P}_{14,6,6,6}\right]^{+}>>[\mathrm{FAP}]^{-}>\left[\mathrm{C}_{6} \mathrm{mim}\right]^{+}>\left[\mathrm{N}_{7,2,2,2}\right]^{+}>\left[\mathrm{C}_{4} \mathrm{mim}\right]^{+}>\left[\mathrm { C } _ { 2 } \mathrm { mim } ^ { + } \approx \left[\mathrm{C}_{4} \mathrm{mpyrr}^{+} \approx\left[\mathrm{C}_{4} \mathrm{py}\right]^{+}>\left[\mathrm{N}_{4,1,1,1}\right]^{+}>\left[\mathrm{S}_{2,2,1}\right]^{+}>>\left[\mathrm{NTf}_{2}\right]^{-}>\left[\mathrm{PF}_{6}\right]^{-}>>\right.\right.} \\
& \mathrm{H}_{2} \mathrm{O}>\left[\mathrm{BF}_{4}\right]^{-}
\end{aligned}
$$




\section{Results and Discussion}

\subsection{Cyclic voltammetry of RTILs in dry vs wet environments}

CV was carried out in different RTILs under a pure oxygen atmosphere at a range of humidity levels from $<1 \mathrm{RH} \%$ up to 95 RH\%. Representative cyclic voltammograms in $\left[\mathrm{N}_{4,1,1,1}\right]\left[\mathrm{NTf}_{2}\right]$ at four different humidity levels are presented in Figure 3. A reversible one-electron reduction to superoxide (see equation 1) was observed in a dry environment (< $1 \mathrm{RH} \%$, black line). The CV shape is typical for an electrochemically quasi-reversible process, which is well reported for the oxygen/superoxide redox couple in RTILs. ${ }^{16}$ At increased humidity levels, the reductive peak current becomes larger and the reduction process became more irreversible, resulting in a decreased superoxide oxidation peak. Ferrocene was added to the solution as an internal reference due to significant potential shifting occurring at the $\mathrm{Pt}$ quasi-RE in the presence of the humidified gas. The voltammograms were shifted so that the midpoint of the ferrocene/ferrocenium redox process was at $0 \mathrm{~V}$, and a substantial shift ( $600 \mathrm{mV}$ ) of the ORR potential, from ca. $-1.3 \mathrm{~V}$ (vs. $\mathrm{Fc} / \mathrm{Fc}^{+}$) at $<1 \mathrm{RH} \%$ (dry) to ca. $-0.7 \mathrm{~V}$ at $95 \mathrm{RH} \%$ (wet) was observed. This is likely due to the increased presence of proton-donors that catalyse the reduction reaction (see equations 2 and 3), which is further supported by the significant increase in the ORR peak current. From $<1$ RH\% to 55 RH\%, a current increase of approximately 2.5 times (from -6 $\mu \mathrm{A}$ to $-15 \mu \mathrm{A}$ ) was observed, indicating a mix of 2 and 4 electron processes, which is supported by the absence of the superoxide oxidation peak. At $95 \mathrm{RH} \%$, the current increased by a factor of three (to $-19 \mathrm{ca}$. $\mu \mathrm{A}$ ), which suggests closer to a 4-electron process is dominating (equation 3). A change in the oxygen diffusion coefficient as the result of viscosity changes in the water-saturated RTIL may also contribute to the increased currents, but a detailed study of this effect is well beyond the scope of this work.

In contrast with $\left[\mathrm{N}_{4,1,1,1}\right]\left[\mathrm{NTf}_{2}\right]$, the peak position vs. the Pt quasi-RE in $\left[\mathrm{P}_{14,6,6,6}\right][\mathrm{FAP}]$ was substantially less affected by humidity (see ESI Figure S2b), and the ORR peak current only showed a 20\% increase, likely owing to the much higher hydrophobicity of the $\left[\mathrm{P}_{14,6,6,6}\right]^{+}$cation compared to $\left[\mathrm{N}_{4,1,1,1}\right]^{+}$(see trend in equation 6 ).

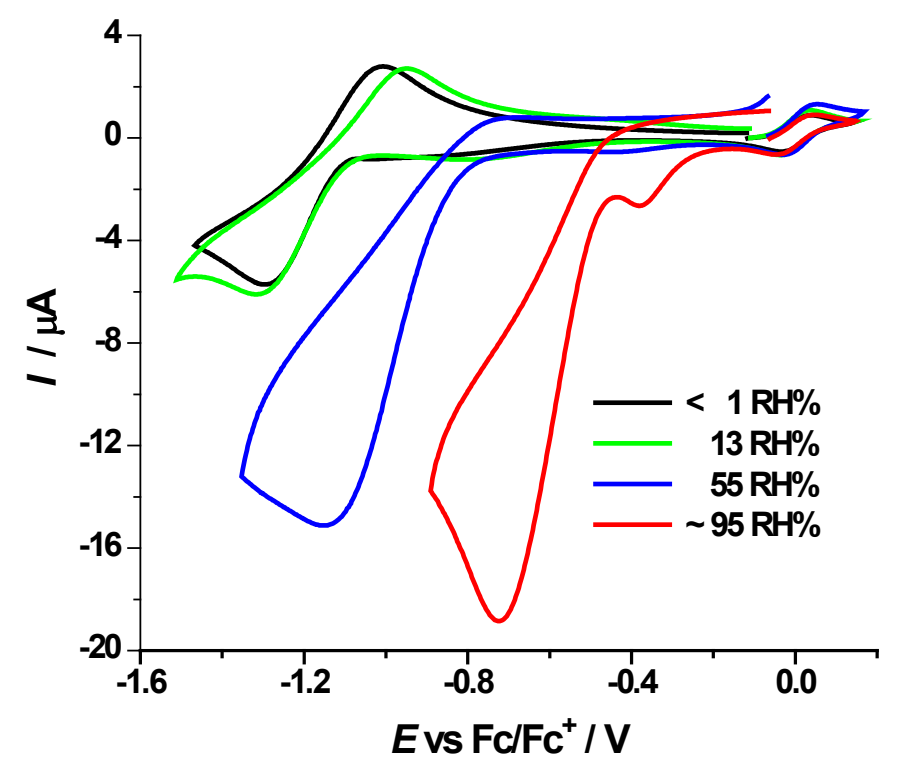

Figure 3. Cyclic voltammograms at $100 \mathrm{mV} \mathrm{s}^{-1}$, in $\left[\mathrm{N}_{4,1,1,1}\right]\left[\mathrm{NTf}_{2}\right]$ on a Pt TFE, with $7 \mathrm{mM}$ ferrocene as internal reference in an $\mathrm{O}_{2}$ saturated flow with RH\% of < 1 RH\% (black), 13 RH\% (green), 55 RH\% (blue) and approximately 95 RH\% (red). 


\subsubsection{Effect of Anion}

The type of anion is known to have a significant impact on the hygroscopic behaviour of RTILs. ${ }^{54,57}$ The bulk solubility of water in ionic liquids containing the $[\mathrm{FAP}]^{-}$anion is much lower compared to $\left[\mathrm{NTf}_{2}\right]^{-},\left[\mathrm{PF}_{6}\right]^{-}$, or $\left[\mathrm{BF}_{4}\right]^{-}-$see trend in equation 6, and also in reference [57]. It was previously shown that electro-absorption of water in the EDL is more pronounced for hydrophilic anions at negative potentials. ${ }^{58}$ In an ionic liquid, absorbed water molecules are known to preferentially interact with the anion. ${ }^{6,47,58-59}$ Hence, it is important to investigate how different anionic species may affect the ORR reaction at different humidity levels. Figure 4 shows the normalised ORR current as a function of increasing humidity levels in four different $\left[\mathrm{C}_{4} \mathrm{mim}\right]^{+}$-based RTILs. The current is mostly unaffected at low humidity levels (< $15 \mathrm{RH} \%$ ) suggesting that the cation is the determining factor at low humidity levels. This is consistent with $\mathrm{AFM}^{32-33,39,60}$ and SEIRAS ${ }^{38}$ studies, where it is well known that the innermost layer at a negatively biased surface is mainly composed by cations. The normalised ORR current then begins to increase above $15 \mathrm{RH}$. The current at high humidity levels (> $95 \mathrm{RH} \%$ ) follows the trend:

$$
[\mathrm{FAP}]^{-}<\left[\mathrm{NTf}_{2}\right]^{-}<\left[\mathrm{PF}_{6}\right]^{-}<\left[\mathrm{BF}_{4}\right]^{-}
$$

which is consistent with the computationally predicted molecular-hydrophobicity and volume trends for individual anionic molecules (see trends 5 and 6), and by COSMO-RS calculations ${ }^{47}$ from a separate study.

For the $\left[\mathrm{BF}_{4}\right]^{-} \mathrm{RTIL}$, there is a lower than expected current trend between 20 and $80 \mathrm{RH} \%$. It was suspected that this may be due to insufficient equilibration time. However, waiting $130 \mathrm{~min}$ instead of $45 \mathrm{~min}$ before recording the first scan did not affect the current response (see ESI Figure S3). Instead, repeated CV scanning caused an increase in the current, suggesting a possible side-reaction and build-up of electrogenerated products contributing to the current. This is not surprising considering that $\left[\mathrm{BF}_{4}\right]^{\text {; }}$, as well as $\left[\mathrm{PF}_{6}\right]^{-}$, can undergo hydrolysation. ${ }^{61}$ At $90 \mathrm{RH} \%$, the electrogenerated products are likely saturated at the EDL from the initial scan; consecutive scans at this humidity level can cause severe changes in the ORR current due chemical reactions with previously electrogenerated species, such as $\mathrm{H}_{2} \mathrm{O}_{2}$. Overall, the results in Figure 4 suggest that bulky, hydrolytically stable and hydrophobic anions such as [FAP] are recommended for applications where a stable ORR response in humidified environments is required, e.g. for oxygen sensing.

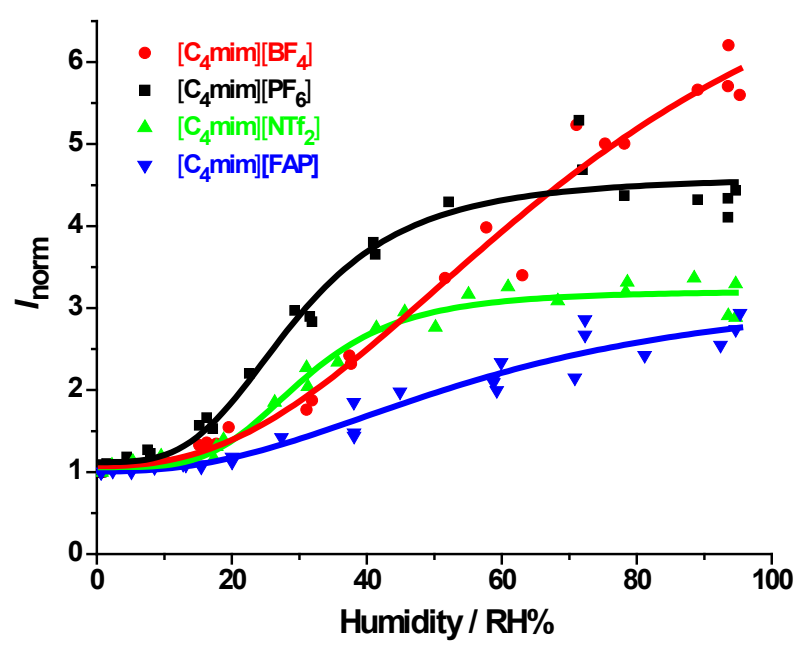

Figure 4. Effect of humidified environments on the normalised current for oxygen reduction in $\left[\mathrm{C}_{4} \mathrm{mim}\right]\left[\mathrm{BF}_{4}\right](\bullet),\left[\mathrm{C}_{4} \mathrm{mim}\right][\mathrm{PF} 6](\bullet)$, $\left[\mathrm{C}_{4} \mathrm{mim}\right]\left[\mathrm{NTf}_{2}\right](\Delta)$ and $\left[\mathrm{C}_{4} \mathrm{mim}\right][\mathrm{FAP}](\nabla)$ with increasing relative humidity percentages (RH\%). CVs (at $100 \mathrm{mVs}^{-1}$ ) were obtained on Pt-TFEs, with each scan was taken after 45 min equilibration time. All experiments were performed at least in triplicate. 


\subsubsection{Effect of cation with a hydrophobic anion, $\left[\mathrm{NTf}_{2}\right]^{-}$}

A negatively polarised electrode during oxygen reduction voltammetry implies that the EDL structure at the electrode-RTIL interface will be dominated by the RTIL cation. In contrast with anions, cations generally only have a slight influence on the solubility of water in RTILs. ${ }^{45,47}$ Properties such as the molecular affinity to water (predicted by SE values), coupled with cation size (based on CPK volumes) - which may sterically hinder the adsorption of other species at the electrode surface (see Table S1 in the ESI) - need to be considered. In this study, only RTILs displaying quasi-reversible ORRs were included, i.e. the pyridinium ionic liquid was omitted due to an irreversible ORR process (see ESI, Figure S7). The presence of an obvious superoxide oxidation peak for the remaining RTILs implies that any impurities in the RTILs (e.g. left over from the synthesis procedure) are minimal, and do not affect the electrochemical processes occurring during the oxygen reduction reaction.

Figure 5 presents normalised ORR peak currents vs. humidity for eight different RTILs sharing the same (moderately hydrophobic) $\left[\mathrm{NTf}_{2}\right]^{-}$anion. Compared to the previous study of different anions (section 3.1.1), the type of cation appears to have a more significant influence on the ORR current at lower humidity levels (i.e. $<40$ RH\%). There is a clear difference between the humidity level at which the ORR current starts to sharply increase - referred to as the "onset-humidity" - typically occurring at below $30 \mathrm{RH} \%$, and follows the trend:

$$
\left[\mathrm{P}_{14,6,6,6}\right]^{+}>\left[\mathrm{C}_{6} \mathrm{mim}\right]^{+}>\left[\mathrm{C}_{4} \mathrm{mim}\right]^{+} \approx\left[\mathrm{N}_{7,2,2,2}\right]^{+} \approx\left[\mathrm{N}_{4,1,1,1,1}\right]^{+}>>\left[\mathrm{C}_{4} \mathrm{mpyrr}\right]^{+} \approx\left[\mathrm{S}_{2,2,1}\right]^{+}>>\left[\mathrm{C}_{2} \mathrm{mim}\right]^{+}
$$

This is in contrast with the different anions discussed in Section 3.1.1, where the onset-humidity appears to be almost unaffected by the type of cation present. Significant variability in the data points towards higher humidity levels (see discussions in section 3.2.3) prevents a confident evaluation of the $95 \mathrm{RH} \%$ current trends, although it is clear that the ORR current in the $\left[\mathrm{P}_{14,6,6,6}\right]^{+} \mathrm{RTIL}$ is much less affected by water compared to the other cations. The variability in current could be due several factors including increased follow-up chemical reactions and even bubble formation at the electrode-RTIL interface due to water-splitting reactions (see Figure S11 in the ESI).

Zhong et al. ${ }^{60}$ reported that at low water content, a stable structuring of the RTIL at the electrode exists and is dominated by the cation. As increasing humidity levels, water molecules begin to disrupt and weaken the structuring of the RTILs at an electrode. Hence, the intermediate RH\% trends are dominated by the tendency of the EDL structure to be affected by the presence of water. The trends at high $\mathrm{RH} \%$ are thus a better reflection of the bulk hydrophobicity of the RTILs. 


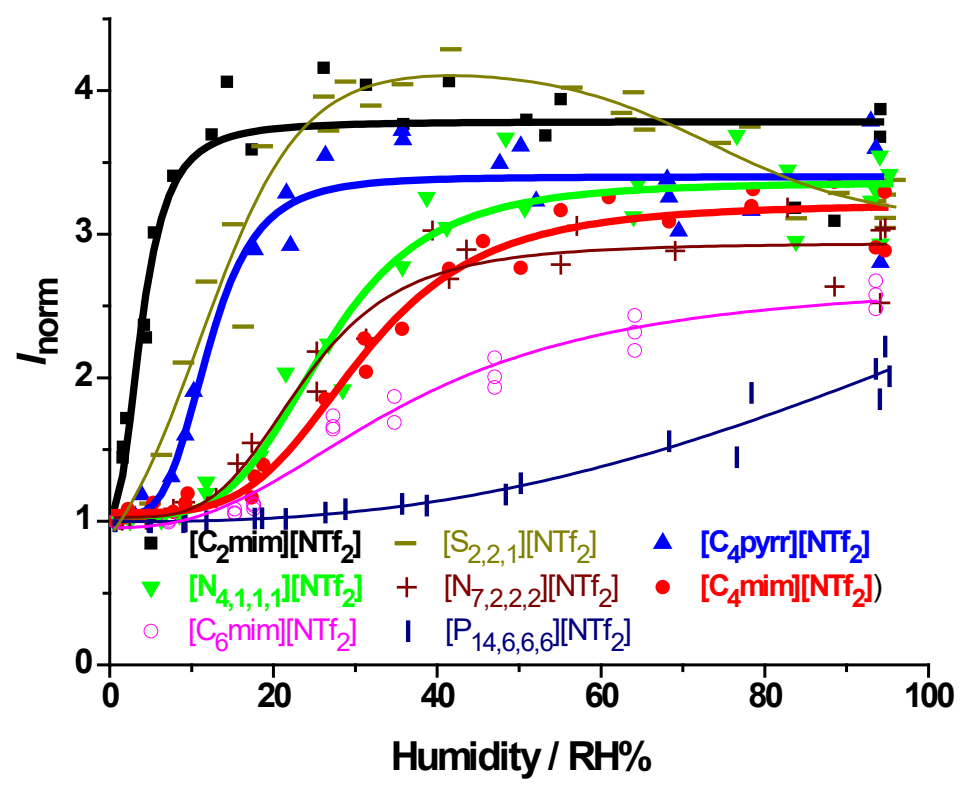

Figure 5. Effect of humidified environments on the normalised current for oxygen reduction in $\left[\mathrm{C}_{2} \mathrm{mim}\right]\left[\mathrm{NTf} f_{2}\right](\boldsymbol{\bullet}),\left[\mathrm{S}_{2,2,1}\right]\left[\mathrm{NTf}_{2}\right](-)$, $\left[\mathrm{C}_{4}\right.$ mpyrr] $\left[\mathrm{NTf}_{2}\right](\boldsymbol{\Delta}),\left[\mathrm{C}_{4} \mathrm{mim}\right]\left[\mathrm{NTf}_{2}\right](\bullet),\left[\mathrm{N}_{4,1,1,1}\right]\left[\mathrm{NTf}_{2}\right](\nabla),\left[\mathrm{N}_{7,2,2,2}\right]\left[\mathrm{NTf}_{2}\right](+),\left[\mathrm{C}_{6} \mathrm{mim}\right][\mathrm{NTf} 2](\bigcirc)$ and $\left[\mathrm{P}_{14,6,6,6}\right]\left[\mathrm{NTf}_{2}\right](\mathrm{I})$ with increasing relative humidity percentage $(\mathrm{RH} \%)$. CVs at $100 \mathrm{mV} \mathrm{s}^{-1}$ were carried out on Pt-TFEs and each scan was taken after $45 \mathrm{~min}$ equilibration time. The scans were taken at $100 \mathrm{mVs}^{-1}$ and with a step potential of $-2.5 \mathrm{mV}$.

Between the three imidazolium-based RTILs, the trends are in order of increasing alkyl chain length, as expected in terms of increased cation hydrophobicity. The ORR in $\left[\mathrm{C}_{2} \mathrm{mim}\right]\left[\mathrm{NTf}_{2}\right]$ appears to be the most affected by the presence of moisture at extremely low humidity levels, where a sharp ORR current increase from 0 to $3 \mathrm{RH} \%$ is present. This is in contrast with the other RTILs where a relatively more stable region of low ORR current vs. humidity is present. The significant dependency of the onset-humidity on the type of cations is a factor to be considered when designing humidity sensors where sensitivity within a particular humidity range is desired; or for the case of an oxygen sensor, where sensitivity to moisture should be avoided. Surface spectroscopy measurements ${ }^{37}$ have shown that imidazolium cations with small alkyl chains (e.g. $\left[\mathrm{C}_{2} \mathrm{mim}\right]^{+}$) tend to align with the aromatic ring structure flat against platinum surfaces. Applying a negative potential stabilizes this conformation, while increasing the alkyl chain length causes a tilting of the planar structure. However, it is surprising that there is a substantial difference in the ORR CV response current behaviour between $\left[\mathrm{C}_{2} \mathrm{mim}\right]^{+}$(black squares), $\left[\mathrm{C}_{4} \mathrm{mim}\right]^{+}$(red circles) and $\left[\mathrm{C}_{6} \mathrm{mim}\right]^{+}$(purple hollow circles) Nevertheless, the longer alkyl chains of $\left[\mathrm{C}_{4} \mathrm{mim}\right]^{+}$and $\left[\mathrm{C}_{6} \mathrm{mim}\right]^{+}$allow the formation of a more hydrophobic innermost layer that prevents accumulation of water near the electrode.

Interestingly, the two ammonium ionic liquids, $\left[\mathrm{N}_{4,1,1,1}\right]\left[\mathrm{NTf}_{2}\right]$ and $\left[\mathrm{N}_{7,2,2,2}\right]\left[\mathrm{NTf} f_{2}\right]$, with significantly different cation alkyl chain lengths, produced similar ORR-current behaviour in Figure 5. A layer of ammonium cations will form at a negatively charged surface. At sufficiently high negative surface polarisation, the positively charged nitrogen group will be pulled towards the negative surface charge, inducing a reorientation of the short alkyl chains. Ultimately, this results in a dense structure of cations at the electrode interface, where longer alkyl groups are expected to point away from the charged surface, orientating in the most stable energetic state to maximise interaction with the anion layer above. However, the three shorter alkyl chains of the ammonium RTILs studied are too short and less flexible to effectively cover the electrode surface area between repelling cations, and do not form a highly dense hydrophobic layer at the electrode interface. This can leave cavities and pathways for water transportation to the electrode surface. 
Furthermore, the positively charged nitrogen atom is less shielded by the shorter alkyl chains. This can allow water molecules to interact via the electronegative oxygen, and with the two aligning hydrogens more strongly attracted to the negatively polarised surface. However, in the case of $\left[\mathrm{P}_{14,6,6,6}\right]\left[\mathrm{NTf}_{2}\right]$, the reorientation of the four long alkyl chains forms a dense hydrophobic layer that prevents the absorption of water in the EDL close to the electrode surface. Hence it is recommended for bulky and highly hydrophobic cations (e.g. $\left.\left[\mathrm{P}_{14,6,6,6}\right]^{+}\right)$to be employed for stable responses with less interaction from water.

\subsubsection{Effect of cation with a highly hydrophobic anion, [FAP] ${ }^{-}$}

Figure 6 shows ORR peak currents vs. humidity for different RTILs with the most hydrophobic [FAP] ${ }^{-}$anion used in this study, and different cations, namely $\left[\mathrm{P}_{14,6,6,6}\right][\mathrm{FAP}],\left[\mathrm{C}_{2} \mathrm{mim}\right][\mathrm{FAP}],\left[\mathrm{C}_{4} \mathrm{mim}\right][\mathrm{FAP}]$, and $\left[\mathrm{C}_{6} \mathrm{mim}\right][\mathrm{FAP}]$. As expected, normalised currents at $>30 \mathrm{RH} \%$ for the $[\mathrm{FAP}]^{-}$-based RTILs are lower than the corresponding $\left[\mathrm{NTf}_{2}\right]^{-}$-based RTILs (Figure 5), because of the higher hydrophobicity of [FAP]- . Additionally, the [FAP] $]^{-}$anion has an onset-humidity of $10 \mathrm{RH} \%$ for $\left[\mathrm{C}_{2} \mathrm{mim}\right][\mathrm{FAP}]$ (Figure 6) which is a significant improvement compared to $\left[\mathrm{C}_{2} \mathrm{mim}\right]\left[\mathrm{NTf}_{2}\right]$ (Figure 4). The onset-humidity follows the trend:

$$
\left[\mathrm{P}_{14,6,6,6}\right]^{+}>>\left[\mathrm{C}_{4} \mathrm{mim}\right]^{+} \approx\left[\mathrm{C}_{6} \mathrm{mim}\right]^{+}>\left[\mathrm{C}_{2} \mathrm{mim}\right]^{+}
$$

Interestingly, the onset-humidity trend for the three imidazolium cations with the [FAP] ${ }^{-}$anion is not as expected, and is different to that observed for $\left[\mathrm{NTf}_{2}\right]^{-}$. It is not entirely obvious as to why it is the case for the [FAP] $]^{-}$-based RTILs, but this unusual behaviour is consistent with a previous AFM study under dry conditions that revealed differences in the packing density of the three imidazolium ionic liquid cations that did not follow the expected trend based of increasing alkyl chain length. ${ }^{33}$

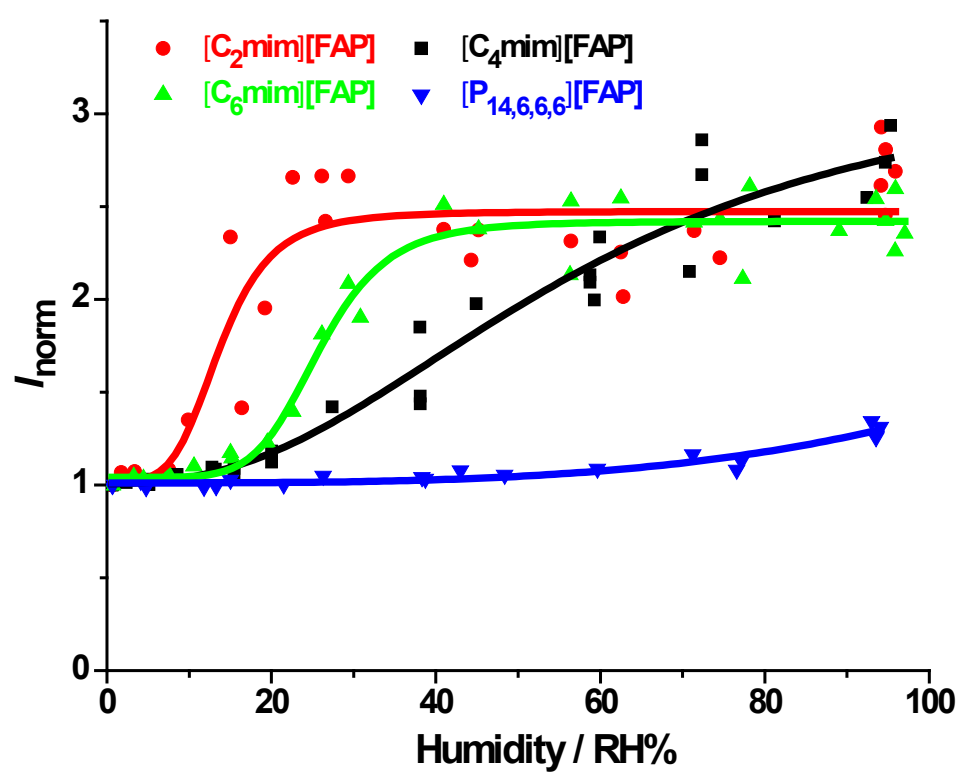

Figure 6. Effect of humidified environments on the normalised current for oxygen reduction of $\left[\mathrm{C}_{2} \mathrm{mim}\right][\mathrm{FAP}](\bullet),\left[\mathrm{C}_{4} \mathrm{mim}\right][\mathrm{FAP}]$ $(\boldsymbol{\nabla}),\left[\mathrm{C}_{6} \mathrm{mim}\right][\mathrm{FAP}](\triangle)$ and $\left[\mathrm{P}_{14,6,6,6}\right][\mathrm{FAP}](\boldsymbol{\nabla})$ with increasing relative humidity percentages (RH\%). CVs were carried out on PtTFEs. Each scan was taken after 45 min equilibration time and all experiments were performed at least in triplicate. The scans were taken at $100 \mathrm{mVs}^{-2}$ and with a step potential of $-2.5 \mathrm{mV}$. 


\subsection{Physical characteristics of the ionic liquid electrical double layer on a Pt-TFE.}

Fedorov and Kornyshev's ${ }^{62}$ study of the ionic liquid (IL) EDL at the electrified solid-IL interfaces reveals a "generally more complicated than expected" structure, due to the tendency of ILs to self-assemble. Previous work suggests an EDL structure that is comparable to aqueous electrolytes, consisting of an adsorbed ion layer succeeded by an electrostatically bound diffuse layer. ${ }^{63-65}$ However, it was found from AFM studies that a multilayer of both single and cation-anion pair layers can form at the interface, and the number of layers increased and were more tightly organised at higher potentials. ${ }^{34,66}$ Here, three RTILs: $\left[\mathrm{C}_{2} \mathrm{mim}\right]\left[\mathrm{NTf} f_{2}\right],\left[\mathrm{N}_{4,1,1,1}\right]\left[\mathrm{NTf}_{2}\right]$, and $\left[\mathrm{P}_{14,6,6,6}\right]\left[\mathrm{NTf}_{2}\right]$ were selected to perform AFM force curve measurements under humidified conditions at ca. $40 \mathrm{RH} \%$ (Figure 7), and will be contrasted with the $\mathrm{CV}$ results in the previous sections. These RTILs represent three distinct behaviours observed in the electrochemical studies above: (case 1 ) $\left[\mathrm{C}_{2} \mathrm{mim}\right]\left[\mathrm{NTf}_{2}\right]$ shows a significant change in ORR current at low humidities, (case 2) $\left[\mathrm{N}_{4,1,1,1}\right]\left[\mathrm{NTf}_{2}\right]$ gives a stable ORR current at low RH\%, and (case 3) $\left[\mathrm{P}_{14,6,6,6}\right]\left[\mathrm{NTf}_{2}\right]$ where the ORR current remains stable up to high moisture contents.

The electrode was held at the open circuit potential (OCP) and biased at $-0.8 \mathrm{~V}$ (vs. the quasi-Pt-RE) to compare effect of a negative surface biasing during ORR on the EDL. Several force-distance curves were collected and one representative curve per sample and condition is used for the discussion. It is noted that the studies were conducted on rough platinum thin-film electrodes which complicates the interpretation of results, but were performed to represent the real conditions used for electrochemical sensing. Three overlayed force-distance curves per sample can be found in the ESI (Figure S10) to show the reproducibility at different areas on the electrode. We note that the layering of RTILs such as $\left[\mathrm{C}_{2} \mathrm{mim}\right]\left[\mathrm{NTf}_{2}\right],{ }^{55}\left[\mathrm{C}_{4}\right.$ mpyrr] $\left[\mathrm{NTf}_{2}\right]^{60}$ or ammonium RTILs ${ }^{38}$ on a flat electrode under 'dry' conditions has been previously reported, but these conclusions may not be valid for a significantly rougher surface.
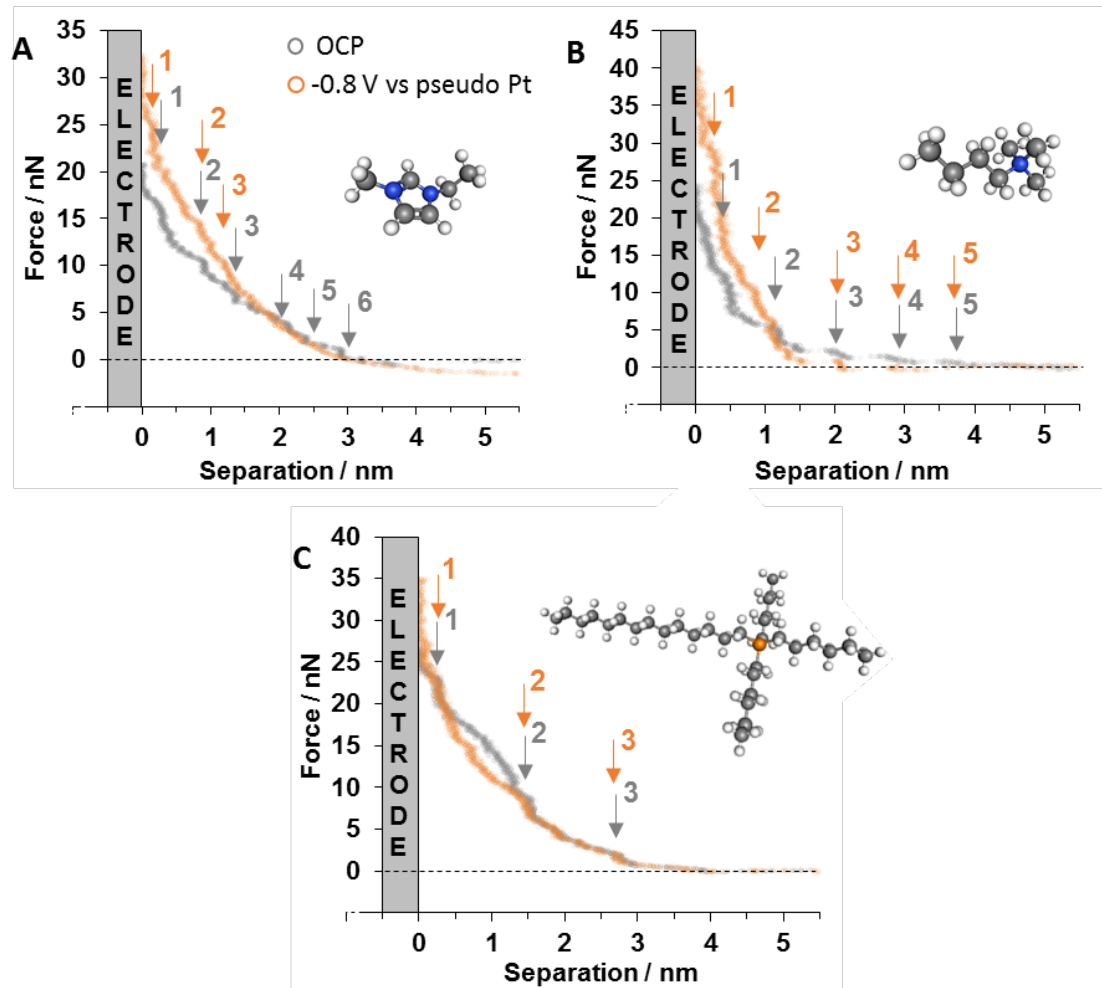

Figure 7. Representative force vs distance curves for a silicon nitride cantilever approaching a Pt-TFE surface at the OCP (grey) and $-0.8 \mathrm{~V}$ (vs. pseudo Pt RE) (orange) in (A) [ $\mathrm{C}_{2}$ mim] $\left[\mathrm{NTf}_{2}\right]$, in (B) $\left[\mathrm{N}_{4,1,1,1}\right]\left[\mathrm{NTf}_{2}\right]$ and in (C) $\left[\mathrm{P}_{14,6,6,6}\right][\mathrm{NTf} 2]$ in $40 \mathrm{RH} \%$ (in air). An overlay of three force-curves for each experimental case can be found in the ESI (Figure S10). 


\subsubsection{General trends in AFM force-curves}

Overall, the force-curves in Figure 7 for both charged and uncharged surfaces show step-like features, superimposed on a broad curve with the force gradually increasing towards $0 \mathrm{~nm}$ separation. The broad curve is related to the compression of stable EDL structures by the tip as well as the interaction of the tip with the rough electrode surface. The steps correspond to tip-interaction with structured layers of molecules (e.g. cations, anions, water, etc.) orientated and assembled over the electrode surface. Subtle step-features are also present in between the more pronounced ones, which are attributed to either different conformations of ions, the presence of interstitial water or may be caused by roughness of the electrode surface. In the following discussions, the more pronounced layers will be referred to as layers 1, 2, 3, etc., with layer 1 being the surface-adsorbed innermost ion layer.

The thickness of the EDL can be observed by the occurrence of a "snap-on" event. This is defined as the distance at which the descending tip experiences the first significant attractive force towards the diffuse layer, and is observed as an abrupt drop in the measured force coinciding with the start of the compression behaviour. Within the EDL, the pronounced layer-thicknesses can be estimated by measuring the width between each step of the force-curves, and are expected to be a function of the ion or ion-pair sizes. The force required for the AFM tip to puncture through a layer is referred to as the "push-through" force. Zhong et al. ${ }^{60}$ reported that the EDL of $\left[\mathrm{C}_{4} \mathrm{mpyrr}\right]\left[\mathrm{NTf} \mathrm{f}_{2}\right]$ is structurally weakened in the presence of water, even at very low water contents around $66 \mathrm{ppm}$. Based on the results shown in figure 5, $\left[\mathrm{C}_{2} \mathrm{mim}\right]\left[\mathrm{NTf} f_{2}\right],\left[\mathrm{S}_{2,2,1}\right]\left[\mathrm{NTf} f_{2}\right]$ and $\left[\mathrm{C}_{4} \mathrm{mpyrr}\right]\left[\mathrm{NTf} \mathrm{f}_{2}\right]$ show an early onset humidity, meaning that there is a significant amount of water present in the EDL even at low humidity levels. This is in contrast to the research reported by Cheng et al., where AFM studies were carried out in dry and humidified $\left[\mathrm{C}_{2} \mathrm{mim}\right]\left[\mathrm{NTf}_{2}\right]$ on mica surfaces, with a silica-terminated silicon AFM tip (of 5-10 nm radius). ${ }^{55}$ The steps appeared more pronounced under humidified conditions (43 RH\%), and a negligible compression behaviour was observed. This is probably because of the atomically smooth and uniform surface of Mica as well as the fact that water is required to charge the Mica surface. The uniformly charged and smooth surface of Mica allows highly ordered establishment of the first layer, which can then allow more ordered subsequent layers to form, whereas more disordered and less defined structures are expected on the rougher Pt-TFE surface used in our study (see discussions in ESI).

Also, an interface-selective vibrational spectroscopy study on the behaviour of ammonium ILs at Au interfaces showed that alkyl chains form a loose structure that reaches into the anion layer, resulting in a more interdigitated structure rather than a clearly separated alternating cation/anion layer. ${ }^{38}$ This behaviour could further add to the contribution of the superimposed compression-like feature, especially for the longer chain RTILs (e.g. $\left[\mathrm{P}_{14,6,6,6}\right]\left[\mathrm{NTf} \mathrm{f}_{2}\right]$ ). For this work, we have chosen to examine the EDL on the non-ideal Pt-TFE (also used for the CV experiments) since this is a more typical representation of an electrode surface found in real sensors.

\subsubsection{Comparison of the EDLs of individual RTILS}

To aid with the discussion, estimations of the layer thicknesses were obtained from computationally optimised molecular structures of each ion, as shown in Figure S13 in the ESI. Orientations of the ions were based on suggestions 
from other research. ${ }^{37-38}$. Since only the first few layers are expected to have a strong influence on the electrochemistry at the Pt-RTIL interface, they will be focussed on in the following sections.

\section{Case 1: Unbiased electrode (at OCP)}

In $\left[\mathrm{C}_{2}\right.$ mim] $\left[\mathrm{NTf}_{2}\right]$ and $\left[\mathrm{N}_{4,1,1,1}\right]\left[\mathrm{NTf}_{2}\right]$ several pronounced layers (Figures $7 \mathrm{~A}$ and $7 \mathrm{~B}$ grey arrows) are visible in the force-curves. However, in $\left[\mathrm{P}_{14,6,6,6}\right]\left[\mathrm{NTf}_{2}\right]$ no pronounced layers are discernible. During tip-engagement, the initial interaction with the EDL is with the diffuse layer, which typically occurs at a separation between 3.5 and $4.5 \mathrm{~nm}$. For $\left[\mathrm{C}_{2} \mathrm{mim}\right]\left[\mathrm{NTf}_{2}\right]$ the initial "snap-on" behaviour occurs from ca. $4.5 \mathrm{~nm}$ to ca. $3.8 \mathrm{~nm}$, which could indicate a higher degree of water-incorporation into the EDL structure compared to the bulk RTIL.

In $\left[\mathrm{C}_{2} \mathrm{mim}\right]\left[\mathrm{NTf}_{2}\right]$, layer thicknesses are approximately $0.3 \mathrm{~nm}$ (layer 1), $0.63 \mathrm{~nm}$ (layer 2), and $\sim 0.51 \mathrm{~nm}$ each for layers 3,4 and $5 .\left[\mathrm{C}_{2} \mathrm{mim}\right]^{+}$is known to rest relatively flat and well-ordered on the surface. ${ }^{37}$ The stability of this orientation will determine the effectiveness of the cation to block moisture adsorption the electrode surface. Comparing the layer thicknesses with Figure 7, it can be assumed that the innermost layer almost equals the size of a cation $(\approx 0.25 \mathrm{~nm})$, followed by an anion layer $(\approx 0.6 \mathrm{~nm})$, as expected. Further layers are significantly thicker (around $0.5 \mathrm{~nm}$ ) that would match a water + cation layer, or an anion layer. So the layer thickness suggests water incorporation between the ion layers, which was also concluded by Zhong et al. for [ $\left.\mathrm{C}_{4} \mathrm{mpyrr}\right]\left[\mathrm{NTf}_{2}\right]{ }^{60}$

$\left[\mathrm{N}_{4,1,1,1}\right]\left[\mathrm{NTf}_{2}\right]$ has approximately the following layer thicknesses: $0.5 \mathrm{~nm}$ (layer 1), $1.1 \mathrm{~nm}$ (layer 2), and the subsequent three layers are ca. 0.7-0.9 nm thick. Again, it can be assumed based on previous research that the innermost layer is formed by cations, followed by an anion layer. However, in this case no separate cation and anion layers can be detected and therefore it cannot be determined whether there is water incorporation or simply a less well separated cation-anion layer due to the presence of the longer alkyl chain. It may even be possible that the innermost layer is formed of a cation bilayer followed by the expected cation-anion double layers as predicted by Kornyshev et al. for "tricky quaternary structures in combination with more compact anions". ${ }^{67}$ Examining the structure of $\left[\mathrm{N}_{4,1,1,1}\right]^{+}$, the three short methyl groups (believed to be facing the electrode surface) would not be effective at shielding the localised positive charge on the nitrogen atom, allowing interaction with the water molecules and preventing adsorption on the Pt-surface. The absence of a "snap-on" behaviour, indicates that there is insignificant water incorporation within the EDL of this RTIL, and is consistent with the results in Figure 5. However it can be seen that the innermost layer is thicker for $\left[\mathrm{N}_{4,1,1,1}\right]^{+}$compared to $\left[\mathrm{C}_{2} \mathrm{mim}\right]^{+}$.

In contrast, $\left[\mathrm{P}_{14,6,6,6}\right]\left[\mathrm{NTf}_{2}\right]$ does not form very prominent layers. Most force curves in this RTIL were dominated by a very obvious compression-like behaviour without obvious structuring. These features could be associated with conformational changes of the long (14-carbon) alkyl chains coupled with re-organisation of anions sandwiched between the cation layers that are held in an interdigitated pattern. Like with $\left[\mathrm{N}_{4,1,1,1}\right]\left[\mathrm{NTf}_{2}\right]$, no initial "snap-on" behaviour was present in $\left[\mathrm{P}_{14,6,6,6}\right]\left[\mathrm{NTf}_{2}\right]$, which suggests an insignificant amount of water-incorporation into the EDL, consistent with the electrochemistry results. In summary, even on the rough Pt surface, ionic liquid structuring in the EDL can be observed in humid environments for the smaller cations, but no conclusions can be drawn for the larger 
phosphonium one - characterization on a flat electrode or SEIRAS measurements are required to determine whether structuring is present or not.

\section{Case 2: Biased Pt electrode (at $-0.8 \mathrm{~V}$ )}

At a negatively biased Pt surface, the force-curves for $\left[\mathrm{C}_{2} \mathrm{mim}\right]\left[\mathrm{NTf}_{2}\right]$ and $\left[\mathrm{N}_{4,1,1,1}\right]\left[\mathrm{NTf} f_{2}\right]$ (Figures $7 \mathrm{~A}$ and $7 \mathrm{~B}$, orange) reveal greater forces on the cantilever below a separation of $\sim 1.5 \mathrm{~nm}$ compared to the unbiased case. In general, higher forces are required to push through the innermost layers which are composed of more ordered cations that are attracted more strongly to the negatively charged surface, as previously reported by Rivera-Rubero et al. ${ }^{37}$ However, for $\left[\mathrm{P}_{14,6,6,6}\right]\left[\mathrm{NTf}_{2}\right]$, the long hydrophobic alkyl chains are able to significantly shield the influence of the surface electric field, thus reducing the stabilising effect of a negative potential bias and therefore no obvious changes in the structuring can be seen. Our experimental results agree well with a molecular dynamics simulation study, ${ }^{48}$ and also support the CV observations for the $\left[\mathrm{P}_{14,6,6,6}\right]^{+}$-based RTILs in Figures 5 and 6.

Under negative potential biasing and above a separation of $0.5 \mathrm{~nm}$, less pronounced steps are observed in humidified [ $\left.\mathrm{C}_{2} \mathrm{mim}\right]\left[\mathrm{NTf}_{2}\right]$ (Figure 7A orange) as a result of water molecules competing for space with ions in the layers and therefore weakening the layering compared to the unbiased surface (Figure 7A grey) or dry environment. ${ }^{34,60,66}$ In contrast, a higher number of pronounced layers are observed on the charged Pt electrode in $\left[\mathrm{N}_{4,1,1,1}\right]\left[\mathrm{NTf}_{2}\right]$, which may hint at less disruption from an increased number of water molecules incorporating in the EDL and competing for space with the RTIL ions under humidified conditions. For $\left[\mathrm{P}_{14,6,6,6}\right]\left[\mathrm{NTf}_{2}\right]$, the much longer alkyl group of the cation prevents condensed and stable structures from forming, but shielding of the positive charge coupled with the high hydrophobicity inhibits the incorporation of polar water molecules into the EDL. Furthermore, at distances $>1.5 \mathrm{~nm}$, the layers remain relatively unaffected by negative biasing, which further substantiates this interpretation. In conclusion, potential biasing results in an increased force required to push through the innermost layers, and for the small RTIL cations, obvious structural layers begin to vanish due to the competition between water and IL ions. 


\section{Conclusions}

The ORR mechanism was studied by CV on Pt-TFEs in several different RTILs under humidified conditions. Peak potentials and currents were found to vary with humidity levels, showing a gradual shift in the reduction mechanism with increasing humidity (from $<1$ to $95 \mathrm{RH} \%$ ). The degree by which a given RTIL is susceptible to humidity changes was found to be a function of ion size, structure, and water affinity. Generally speaking, the cation influences the ORR current at humidity levels below $40 \mathrm{RH} \%$ due to the more pronounced structuring of the ions near the negatively charged electrode, while the anion has a more significant impact on the ORR reaction above $65 \mathrm{RH} \%$ where water molecules begin to disintegrate the EDL structures. AFM force-curve results indicated that water is present at the electrode-RTIL interface in $\left[\mathrm{C}_{2} \mathrm{mim}\right]\left[\mathrm{NTf}_{2}\right]$ and $\left[\mathrm{N}_{4,1,1,1}\right]\left[\mathrm{NTf}_{2}\right]$, but is not detected in the hydrophobic RTIL $\left[\mathrm{P}_{14,6,6,6}\right]\left[\mathrm{NTf} f_{2}\right]$, which agrees well with the CV results. A much greater level of water incorporation in $\left[\mathrm{C}_{2} \mathrm{mim}\right]\left[\mathrm{NTf}_{2}\right]$ was detected, which explains why the ORR current in this RTIL was highly affected by the presence of moisture even at extremely low humidity levels (e.g. $<5$ RH \%). The innermost EDL layers are stabilised at the negatively polarised electrode, and the water layer near the electrode-RTIL interface becomes more apparent in $\left[\mathrm{C}_{2} \mathrm{mim}\right]\left[\mathrm{NTf} \mathrm{f}_{2}\right]$ and $\left[\mathrm{N}_{4,1,1,1}\right]\left[\mathrm{NTf}_{2}\right]$ due to the presence of ions and/or water molecules whereas the outer layers vanish due to the water incorporation. However, in $\left[\mathrm{P}_{14,6,6,6}\right]\left[\mathrm{NTf} f_{2}\right]$, the longer alkyl chain of the cation reduces the layering effect of the negative surface bias, and even at an electrode bias of $-0.8 \mathrm{~V}$, no indication of a water-layer at the electrode-RTIL interface was observed. These results suggest that for applications where a stable ORR current response is necessary, the use of highly hydrophobic and large RTIL cations and anions (e.g. $\left[\mathrm{P}_{14,6,6,6}\right]^{+}$and [FAP]') is recommended. Alternatively, if a large change with humidity is desired (e.g. for humidity sensors), the choice of hydrophillic ionic liquids could be favourably exploited.

\section{Acknowledgements}

This work was supported by an Australian Research Council (ARC) Future Fellowship Award (FT170100315) for DSS. The authors thank both Professor Christopher Hardacre and Professor Rob Atkin for kind donation of two of the RTILs used in this work. The authors acknowledge the use of equipment of the instruments of the Scanning Probe Microscopy facility of the CIFMI/Discipline of Chemistry at Curtin University, funded by ARC LIEF grant number LE130100121. 


\section{References}

1. Stetter, J. R.; Li, J., Amperometric Gas Sensors - a Review. Chem. Rev. 2008, 108, 352-366.

2. Xiong, L.; Compton, R. G., Amperometric Gas Detection: A Review. Int. J. Electrochem. Sci. 2014, 9, 7152-7181.

3. Freeman, B. D., Basis of Permeability/Selectivity Tradeoff Relations in Polymeric Gas Separation Membranes. Macromolecules 1999, 32.

4. Buzzeo, M. C.; Hardacre, C.; Compton, R. G., Use of Room Temperature lonic Liquids in Gas Sensor Design. Anal. Chem. 2004, 76, 4583-4588.

5. Malvaldi, M.; Chiappe, C., From Molten Salts to lonic Liquids: Effect of lon Asymmetry and Charge Distribution. J. Phys.: Condens. Matter 2008, 20, 035108.

6. Freire, M. G.; Santos, L. M. N. B. F.; Fernandes, A. M.; Coutinho, J. A. P.; Marrucho, I. M., An Overview of the Mutual Solubilities of Water-Imidazolium-Based Ionic Liquid Systems. Fluid Ph. Equilibria 2007, 261, 449-454.

7. Welton, T., Room-Temperature lonic Liquids. Solvents for Synthesis and Catalysis. Chemical Reviews 1999, 99, 2071-2084.

8. Buzzeo, M. C.; Evans, R. G.; Compton, R. G., Non-Haloaluminate Room-Temperature lonic Liquids in Electrochemistry-a Review. ChemPhysChem 2004, 5, 1106-1120.

9. Shiddiky, M. J. A.; Torriero, A. A. J., Application of lonic Liquids in Electrochemical Sensing Systems. Biosens Bioelectron 2011, 26, 1775-1787.

10. Shvedene, N. V.; Chernyshov, D. V.; Pletnev, I. V., Ionic Liquids in Electrochemical Sensors. Russian Journal of General Chemistry 2008, 78, 2507-2520.

11. Silvester, D. S., Recent Advances in the Use of Ionic Liquids for Electrochemical Sensing. Analyst 2011, 136, 4871-4882.

12. Marsh, K. N.; Boxall, J. A.; Lichtenthaler, R., Room Temperature lonic Liquids and Their Mixtures- a Review. Fluid Ph. Equilibria 2004, 219, 93-98.

13. Barrosse-Antle, L. E.; Bond, A. M.; Compton, R. G.; O'Mahony, A. M.; Rogers, E. I.; Silvester, D. S., Voltammetry in Room Temperature lonic Liquids: Comparisons and Contrasts with Conventional Electrochemical Solvents. Chemistry - An Asian Journal 2010, 5, 202-230.

14. Hayyan, M.; Mjalli, F. S.; Hashim, M. A.; AlNashef, I. M.; Mei, T. X., Investigating the Electrochemical Windows of lonic Liquids. J. Ind. Eng. Chem. 2013, 19, 106-112.

15. Rehman, A.; Zeng, X., Methods and Approaches of Utilizing lonic Liquids as Gas Sensing Materials. RSC Adv. 2015, 5, 58371 - 58392.

16. Khan, A.; Gunawan, C. A.; Zhao, C., Oxygen Reduction Reaction in lonic Liquids: Fundamentals and Applications in Energy and Sensors. ACS Sustain. Chem. Eng. 2017, 5, 3698-3715.

17. Chi, X.; Tang, Y.; Zeng, X., Electrode Reactions Coupled with Chemical Reactions of Oxygen, Water and Acetaldehyde in an Ionic Liquid: New Approaches for Sensing Volatile Organic Compounds. Electrochimica Acta 2016, 216, 171-180.

18. Lee, J.; Silvester, D. S., Electrochemical Detection of Explosive Compounds in an Ionic Liquid in Mixed Environments: Influence of Oxygen, Moisture, and Other Nitroaromatics on the Sensing Response. Australian Journal of Chemistry 2018.

19. Barnes, A. S.; Rogers, E. I.; Streeter, I.; Aldous, L.; Hardacre, C.; Wildgoose, G. G.; Compton, R. G., Unusual Voltammetry of the Reduction of $\mathrm{O}_{2}$ in $\left[\mathrm{C}_{4} \mathrm{dmim}\right]\left[\mathrm{N}(\mathrm{Tf})_{2}\right]$ Reveals a Strong Interaction of $\mathrm{O}_{2}{ }^{--}$with the $\left[\mathrm{C}_{4} \mathrm{dmim}\right]^{+}$Cation. J. Phys. Chem. C 2008, 112, 13709-13715.

20. Hayyan, M.; Mjalli, F. S.; Hashim, M. A.; AlNashef, I. M.; Tan, X. M., Electrochemical Reduction of Dioxygen in Bis(Trifluoromethylsulfonyl)Imide Based Ionic Liquids. J. Electroanal. Chem. 2011, 657, 150-157.

21. Katayama, Y.; Onodera, H.; Yamagata, M.; Miura, T., Electrochemical Reduction of Oxygen in Some Hydrophobic Room-Temperature Molten Systems. J. Electrochem. Soc. 2004, 151, A59-A63.

22. Switzer, E. E.; Zeller, R.; Chen, Q.; Sieradzki, K.; Buttry, D. A.; Friesen, C., Oxygen Reduction Reaction in lonic Liquids: The Addition of Protic Species. J. Phys. Chem. C 2013, 117, 8683-8690.

23. Zhang, D.; Okajima, T.; Matsumoto, F.; Ohsaka, T., Electroreduction of Dioxygen in 1-N-Alkyl-3Methylimidazolium Tetrafluoroborate Room-Temperature Ionic Liquids. J. Electrochem. Soc. 2004, 151, D31-D37.

24. Yuan, X.-Z.; Alzate, V.; Xie, Z.; Ivey, D. G.; Qu, W., Oxygen Reduction Reaction in 1-Butyl-1-Methyl-Pyrrolidinium Bis(Trifluoromethanesulfonyl)Imide: Addition of Water as a Proton Species. J. Electrochem. Soc. 2014, 161, A451-A457. 25. Xiong, L.; Barnes, E. O.; Compton, R. G., Amperometric Detection of Oxygen under Humid Conditions: The Use of a Chemically Reactive Room Temperature lonic Liquid to 'Trap' Superoxide Ions and Ensure a Simple One Electron Reduction. Sens. Actuators B 2014, 200, 157-166. 
26. Tian, S.; Hou, Y.; Wu, W.; Ren, S.; Qian, J., Hydrophobic Task-Specific lonic Liquids: Synthesis, Properties and Application for the Capture of $\mathrm{So}_{2}$. J. Hazard. Mat. 2014, 278, 409-416.

27. Fukay, Y.; Ohno, H., Hydrophobic and Polar lonic Liquids. Phys. Chem. Chem. Phys. 2013, 15, 4066-4072.

28. Messadi, A.; Mohamadou, A.; Boudesocque, S.; Dupont, L.; Fricoteaux, P.; Nguyen-Van-Nhien, A.; Courty, M., Syntheses and Characterisation of Hydrophobic lonic Liquids Containing Trialkyl(2-Ethoxy-2-Oxoethyl)Ammonium or N-(1-Methylpyrrolidyl-2-Ethoxy-2-Oxoethyl)Ammonium Cations. J. Mol. Liq. 2013, 184, 68-72.

29. Fuller, J.; Breda, A. C.; Carlin, R. T., lonic Liquid-Polymer Gel Electrolytes from Hydrophilic and Hydrophobic Ionic Liquids. J. Electroanal. Chem. 1998, 459, 29-34.

30. Guan, J.; Li, Y.; Li, J., Stretchable lonic-Liquid-Based Gel Polymer Electrolytes for Lithium-lon Batteries. Ind. Eng. Chem. Res. 2017, 56, 12456-12463.

31. Ruzanov, A.; Lembinen, M.; Jakovits, P.; Srirama, S. N.; Voroshylova, I. V.; Cordeiro, M. N. D. S.; Pereira, C. M.; Rossmeisl, J.; Ivaništšev, V. B., On the Thickness of the Double Layer in lonic Liquids. Phys. Chem. Chem. Phys. 2018, 20, 10275-10285.

32. Hayes, R.; Warr, G. G.; Atkin, R., Structure and Nanostructure in Ionic Liquids. Chem. Rev. 2015, 115, 63576426.

33. Li, H.; Endres, F.; Atkin, R., Effect of Alkyl Chain Length and Anion Species on the Interfacial Nanostructure of Ionic Liquids at the $\mathrm{Au}(111)$-Ionic Liquid Interface as a Function of Potential. Phys. Chem. Chem. Phys. 2013, 15, 1462414633.

34. Hayes, R.; Borisenko, N.; Tam, M. K.; Howlett, P. C.; Endres, F.; Atkin, R., Double Layer Structure of lonic Liquids at the Au(111) Electrode Interface: An Atomic Force Microscopy Investigation. J. Phys. Chem. C 2011, 115, 6855-6863. 35. Perkin, S., lonic Liquids in Confined Geometries. Phys. Chem. Chem. Phys. 2012, 14, 5052-5062.

36. Lauw, Y.; Rodopoulos, T.; Gross, M.; Nelson, A.; Gardner, R.; Horne, D., Electrochemical Cell for Neutron Reflectometry Studies of the Structure of Ionic Liquids at Electrified Interface. Rev. Sci. Instrum. 2010, 81, 074101.

37. Rivera-Rubero, S.; Baldelli, S., Surface Spectroscopy of Room-Temperature lonic Liquids on a Platinum Electrode: A Sum Frequency Generation Study. J. Phys. Chem. B 2004, 108, 15133-15140.

38. Nishi, N.; Minami, K.; Motobayashi, K.; Osawa, M.; Sakka, T., Interfacial Structure at the Quaternary Ammonium-Based Ionic Liquid/Gold Electrode Interface Probed by Surface-Enhanced Infrared Absorption Spectroscopy: Anion Dependence of the Cationic Behavior. J. Phys. Chem. C 2017, 121, 1658-1666.

39. Hoth, J.; Hausen, F.; Mueser, M. H.; Bennewitz, R., Force Microscopy of Layering and Friction in an lonic Liquid. J. Phys. Condens. Matter 2014, 26, 284110.

40. McLean, B.; Li, H.; Stefanovic, R.; Wood, R. J.; Webber, G. B.; Ueno, K.; Watanabe, M.; Warr, G. G.; Page, A.; Atkin, R., Nanostructure of $\left[\mathrm{Li}\left(\mathrm{G}_{4}\right)\right] \mathrm{Tfsi}$ and $\left[\mathrm{Li}\left(\mathrm{G}_{4}\right)\right] \mathrm{No}_{3}$ Solvate lonic Liquids at Hopg and $\mathrm{Au}(111)$ Electrode Interfaces as a Function of Potential. Phys. Chem. Chem. Phys. 2015, 17, 325-333.

41. Zhong, Y.-X.; Yan, J.-W.; Li, M.-G.; Zhang, X.; He, D.-W.; Mao, B.-W., Resolving Fine Structures of the Electric Double Layer of Electrochemical Interfaces in Ionic Liquids with an Afm Tip Modification Strategy. J. Am. Chem. Soc. 2015, 136, 14682-14685.

42. Carstens, T.; Hayes, R.; El Abedin, S. Z.; Corr, B.; Webber, G. B.; Borisenko, N.; Atkin, R.; Endres, F., In Situ Stm, Afm and Dts Study of the Interface 1-Hexyl-3-Methylimidazolium Tris(Pentafluoroethyl)Trifluorophosphate/Au(111). Electrochim. Acta 2012, 82, 48-59.

43. Ivanistsev, V.; O'Connor, S.; Fedorov, M. V., Poly(a)Morphic Portrait of the Electrical Double Layer lonic Liquids. Electrochem. Commun. 2014, 48, 61-64.

44. Fedorov, M. V.; Kornyshev, A. A., Towards Understanding the Structure and Capacitance of Electrical Double Layer in lonic Liquids. Electrochim. Acta 2008, 53, 6835-6840.

45. Feng, G.; Jiang, X.; Qiao, R.; Kornyshev, A. A., Water in lonic Liquids at Electrified Interfaces: The Anatomy of Electrosorption. ACS Nano 2014, 8, 11685-11694.

46. Nikitina, V. A.; Kislenko, S. A.; Nazmutdinov, R. R.; Bronshtein, M. D.; Tsirlina, G. A., Ferrocene/Ferrocenium Redox Couple at $\mathrm{Au}(111) /$ Ionic Liquid and $\mathrm{Au}(111)$ /Acetonitrile Interfaces: A Molecular-Level View at the Elementary Act. J. Phys. Chem. C 2014, 118, 6151-6164.

47. Zhou, T.; Chen, L.; Ye, Y.; Chen, L.; Qi, Z.; Freund, H.; Sundmacher, K., An Overview of Mutual Solubility of lonic Liquids and Water Predicted by Cosmo-Rs. Ind. Eng. Chem. Res. 2012, 51, 6256-6264.

48. Bi, S.; Wang, R.; Liu, S.; Yan, J.; Mao, B.; Kornyshev, A. A.; Feng, G., Minimizing the Electrosorption of Water from Humid lonic Liquids on Electrodes. Nat. Commun. 2018, 9, 5222.

49. Sun, J.; MacFarlane, D. R.; Forsyth, M., Synthesis and Properties of Ambient Temperature Molten Salts Based on the Quaternary Ammonium Ion. Ionics 1997, 3, 356-362. 
50. Wandt, J.; Lee, J.; Arrigan, D.; Silvester, D. S., A Lithium Iron Phosphate Reference Electrode for lonic Liquid Electrolytes. Electrochem. Commun. 2018, 93, 148-151.

51. Lee, J.; Du Plessis, G.; Arrigan, D. W. M.; Silvester, D. S., Towards Imroving the Robustness of Electrochemical Gas Sensors: Impact of Pmma Addition on the Sensing of Oxygen in an lonic Liquid. Anal. Methods 2015, 7, 7327-7335. 52. Wagner, W.; Pruss, A., The lapws Formulation 1995 for the Thermodynamic Properties of Ordinary Water Substance for General Scientific Use. J. Phys. Chem. Ref. Data 2002, 31, 387535.

53. Oyi, V. Humidity Conversion Formulas; B210973EN-F; 2013.

54. O'Mahony, A. M.; Silvester, D. S.; Aldous, L.; Hardacre, C.; Compton, R. G., Effect of Water on the Electrochemical Window and Potential Limits of Room-Temperature lonic Liquids. J. Chem. Eng. Data 2008, 53, 28842891.

55. Cheng, H. W.; Dienemann, J. N.; Stock, P.; Merola, C.; Chen, Y. J.; Valtiner, M., The Effect of Water and Confinement on Self-Assembly of Imidazolium Based Ionic Liquids at Mica Interfaces. Sci. Rep. 2016, 6, 30058.

56. Cheng, H.-W.; Stock, P.; Moeremans, B.; Baimpos, T.; Banquy, X.; Renner, F. U.; Valtiner, M., Characterizing the Influence of Water on Charging and Layering at Electrified Ionic-Liquid/Solid Interfaces. Adv. Mater. Interfaces 2015, 2, 1500159.

57. Ignat'ev, N. V.; Welz-Biermann, U.; Kucheryna, A.; Bissky, G.; Willner, H., New lonic Liquids with Tris(Perfluoroalkyl)Trifluorophosphate (Fap) Anions. J. Fluor. Chem. 2005, 126, 1150-1159.

58. Budkov, Y. A.; Kolesnikov, A. L.; Goodwin, Z. A. H.; Kiselev, M. G.; Kornyshev, A. A., Theory of Electrosorption of Water from lonic Liquids. Electrochim. Acta 2018, 284, 346-354.

59. Khan, I.; Kurnia, K. A.; Mutelet, F.; Pinho, S. P.; Coutinho, J. A. P., Probing the Interactions between lonic Liquids and Water: Experimental and Quantum Chemical Approach. J. Phys. Chem. B 2014, 118, 1848-1860.

60. Zhong, Y.; Yan, J.; Li, M.; Chen, L.; Mao, B., The Electric Double Layer in an Ionic Liquid Incorporated with Water Molecules: Atomic Force Microscopy Force Curve Study. ChemElectroChem 2016, 3, 2221-2226.

61. Freire, M. G.; Neves, C. M. S. S.; Marrucho, I. M.; Coutinho, J. A. P.; Fernandes, A. M., Hydrolysis of Tetrafluoroborate and Hexafluorophosphate Counter lons in Imidazolium-Based lonic Liquids. J. Phys. Chem. A 2010, $114,3744-3749$.

62. Fedorov, M. V.; Konrnyshev, A. A., lonic Liquids at Electrified Interfaces. A. Chem. Rev. 2014, 114, 2978-3036.

63. Feng, G.; Zhang, J. S.; Qiao, R., Microstructure and Capacitance of the Electrical Double Layers at the Interface of Ionic Liquids and Planar Electrodes. J. Phys. Chem. C 2009, 113, 4549-4559.

64. Lockett, V.; Horne, M.; Sedev, R.; Rodopoulos, T.; Ralston, J., Differential Capacitance of the Double Layer at the Electrode/lonic Liquids Interface. Phys. Chem. Chem. Phys. 2010, 12, 12499-12512.

65. Lockett, V.; Sedev, R.; Harmer, S.; Ralston, J.; Horne, M.; Rodopoulos, T., Orientation and Mutual Location of Ions at the Surface of Ionic Liquids. Phys. Chem. Chem. Phys. 2010, 12, 13816-13827.

66. Hayes, R. Structure in Ionic Liquids. The University of Newcastle, Australia, 2014.

67. Kornyshev, A. A., Double-Layer in lonic Liquids: Paradigm Change? J. Phys. Chem. B 2007, 111, 5545-5557. 